people with whom he was speaking. Headaches and changes in concentration abilities resolved within 4 months, whereas visual symptoms still persisted after 8 months of drug abstinence, although slightly reduced in intensity.

Neuro-ophthalmic evaluation, including visual acuity, visual fields, stereopsis using the Titmus test, colour perception, and pattern visually evoked response, failed to demonstrate any abnormality. Neurological examination was normal, including electroencephalogram and computed tomography scan.

\section{Comment}

Disturbances of visual perception following cannabinoid consumption are poorly defined. In the report by Levi and Miller,' a patient who misused marijuana alone, like ours, experienced visual changes, including alteration in depth perception and some kind of sensorial disconnection when talking to people. In addition, both subjects experienced intermittent light phenomena; in one as a strobe-like effect, and in the other as bright spots flickering randomly at high frequency.

In our patient, increasing the brightness of the background, even if this was only reading from a bright white paper, enhanced the visual symptoms. In a number of conditions, abnormal sensory phenomena increase as background luminance increases - for example, pain during attacks of migraine, or dazzling in subjects with optic neuropathy. Various mechanisms might be considered as explaining the influence of ambient light, including opticotrigeminal summation ${ }^{2}$ in migraine headache, and intermittent blocks in nerve conduction ${ }^{3}$ in optic neuropathy. In our observation, mechanisms by which visual alterations are increased with a light background are still poorly understood. As concentration was altered, it is conceivable that cortical disinhibition was involved.

Visual abnormalities were also increased by stress in the patient described by Levi and Miller, and by physical effort in ours. It is possible that changes in vasomotor control, which have been shown to occur following cannabinoid misuse, ${ }^{4}$ might play a role in such circumstances.

The visual changes in our patient appeared on the day following discontinuation of hashish misuse. This indicates that, following cannabinoid consumption as with other drugs, ${ }^{1}$ persistent changes in vision can occur after a drug-free interval. Lasting effects of cannabinoid misuse are more frequent than would appear from published reports. However, this diagnosis should only be made after other causes of nonspecific alteration in visual perception have been excluded by a careful history and by medical and neuroimaging evaluation.

\footnotetext{
1 Levi L, Miller NR. Visual illusions associated with previous drug abuse. 7 Clin Neuro-ophthalmol 1990; 10: 103-10.

2 Eckardt LB, McLean JM, Goodell H. Experimental studies on headache: the genesis of pain from the eye. In: Proceedings of the Association for Research in Nervous and Memtal Diseases. Baltimore: Williams \& Wilkins, 1943; 23: 209-27.

3 Safran AB, Bader C, Brazitikos P, de Weisse C, Désangles D. Increasing short-term fluctuation by increasing the intensity of the fixation aid during perimetry. Am f Ophthalmol 1992; 113: 193-7.

4 Katzung BG, Trevor AJ. Pharmacology. 2nd ed. San Francisco: Appleton and Lange, 1989: 167-73.
}

\title{
Dirofilariasis: an uncommon parasitosis of the eye
}

\author{
Merih Soylu, Kadri Özcan, Müslime Yalaz, Seyhan Varinli, Gülhan Slem
}

University of Çukurova

Medical Faculty, Adana,

Turkey

Department of

Ophthalmology

M Soylu

\section{Department of Parasitology K Özcan}

Department of Ophthalmology M Yalaz

Department of Pathology $S$ Varinli

G Slem

Correspondence to:

Dr M Soylu, Cukurova

University Medical Faculty,

Department of

Ophthalmology, Balcal,

Adana, Turkey.

Accepted for publication

19 March 1993
Dirofilariasis, a disease rarely seen in humans, occurs commonly in carnivorous mammals. Two important species in the Dirofilaria genus are found in the eye. One of these is $D$ tenuis, whose natural host is raccoons. As there are no raccoons in Turkey, this parasite is not found there. The other is $D$ repens, which is found in dogs and cats. Since only immature forms are found in humans, no microfilarias are detected in the circulation. ${ }^{12}$ Although it is an uncommon parasite in humans, when found it is usually located in the subepithelial tissues of the eyelids, fingers, cheeks, breasts, abdomen, and very rarely in conjunctivae. The source and the route of infection is not known definitely. Diagnosis could only be made by detecting the parasite in the histological specimen. Treatment is only by surgical excision. ${ }^{1-4}$

\section{Case reports}

CASE 1

A 22-year-old man, complaining of photophobia, redness, and conjunctival swelling in the left eye of 1 week's duration, was admitted to hospital. In the ophthalmic evaluation a ciliary injection and a superotemporally located subconjunctival mass were detected (Fig 1). The mass contained a thin, white living worm. Routine blood tests were within normal limits, and no microfilaria were detected in the blood smear. The worm was removed with a forceps, the subconjunctival mass was excised with the conjunctiva, and the exposed sclera was covered by Tenon's capsule under local anaesthesia. The specimen measured $1 \times 0.5 \mathrm{~cm}$ and histopathologically exhibited a mixed inflammatory 
Figure 1 Clinical appearance of case 1 , subconjunctival swelling disclosing the moving, coiled nematode, located superotemporally in the bulbar conjunctivae.

Figure 2 Several sections of coiled nematode surrounded by mixed inflammatory cell infiltrate (haematoxylin and eosin, $\times 240$ )

Figure 3 Anterior rounded end of $\mathrm{D}$ repens $(\times 90)$.

Figure 4 Clinical appearance of case 2 , diagnosed as orbital pseudotumour.

Figure 5 During biopsy, the moving nematode was found and removed by forceps.
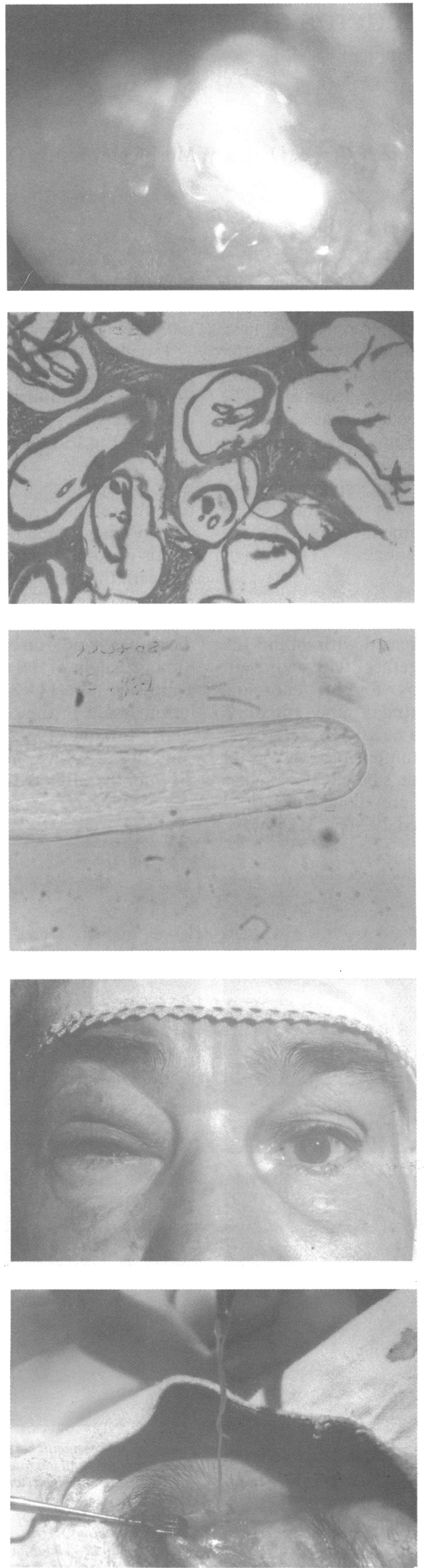

infiltrate and a moderate number of eosinophils around the transverse sections of the nematode (Fig 2). In a parasitological evaluation the nematode was $95 \mathrm{~mm}$ long and $0.46 \mathrm{~mm}$ wide. It had a rounded anterior tip without a mouth cavity (Fig 3). The worm was identified as the immature female form of $D$ repens. No systemic treatment was given to the patient. The postoperative period was uneventful.

CASE 2

A 77-year-old woman had a slowly growing lesion involving the right upper eyelid for 2 months. Ophthalmic examination disclosed a $5 \times 10 \mathrm{~mm}$ solid mass and oedema of the upper eyelid (Fig 4). The mass was clinically diagnosed as an orbital pseudotumour. Orbital computed tomography confirmed the diagnosis. There was no pathology in routine blood tests and smears. An orbital biopsy was planned. At surgery the lesion was noted to lie deep in the orbit, and a moving parasite was detected and removed with a forceps (Fig 5). The tissue surrounding the parasite was excised. Microscopically the lesion disclosed a granulomatous inflammatory reaction. The parasite was $102 \mathrm{~mm}$ long and the widest region was $0.55 \mathrm{~mm}$. In the parasitological investigation it was identified as the immature female form of $D$ repens.

\section{Comment}

A small number of cases of dirofilariasis have appeared in published reports. The most common sites of involvement of the ocular adnexa are the subcutaneous tissues of the eyelids and periorbital region. ${ }^{1-7}$ Subconjunctival involvement is relatively uncommon. The greatest incidence of known human infestation with Dirofilaria occurs in Italy, Sri Lanka, and in the south eastern part of the United States. ${ }^{6}$ Only two cases of dirofilariasis in the eye have been reported in Turkey. ${ }^{89}$ The cases reported in our study were found to be interesting as there were no previous reports from the Çukurova region, located in the southern part of Turkey.

Although rare, dirofilariasis should be taken into account in epidemiological and parasitological studies, and should be considered in the differential diagnosis of the cases with orbital pseudotumour and conjunctivitis.

1 Beaver PC, Jung RC, Cupp EW, eds. Clinical parasitology, 9th Ed. Philadelphia: Lee and Febiger, 1984; Ch 23: 387-92.

2 Kean BH, Sun T, Ellsworth RM, eds. Color atlas/text of ophthalmic parasitology. New York: Igaku-Shoin, 1991; Part 16: 128-34.

3 Duke-Elder S, MacFaul PA. Ocular adnexa, lacrimal, orbital, and paraorbital diseases. In: Duke-Elder, ed. System of ophthalmology. London: Henry Kimpton, 1974; Part 2 Vol XIII: 921 .

4 Raymond LA, Guiterrez Y. Parasitic disease dirofilariasis. In: Fraunfelder FT, Roy FH, eds. Current ocular therapy 2. Philadelphia: Saunders, 1965: 71-2.

5 Thomas D, Older JJ, Kandawalla NM, Torczynski E. The dirofilaria parasite in the orbit. Am F Ophthalmol 1976; 82: 931-3.

6 Font RL, Neafie RC, Perry HD. Subcutaneous dirofilariasis of the eyelid and ocular adnexa. Report of six cases. Arch Ophthalmol 1980; 98: 1079-82.

7 Jariya P, Sucharit S. Dirofilaria repens from the eyelid of a woman in Thailand. Am f Trop Med Hyg 1983; 32: 1456-7.

$8 \mathrm{Kart} S$, Soytürk MK, Erker H, Bilgin S. A rarely seen parasitosis of the eye (Dirofilaria conjunctiva). Turkish Ophthalmol Bull 1988; 18: 192-6.

9 Pazarlı H, Oğuz V, Kaner G, Demiroğlu U. A case of 20: 285-6.
2ubconjunctival dirofilariasis. Turkish Ophthalmol Bull 1990; 